\title{
$B R C A 1$ and BRCA2 mutations and clinical interpretation in 398 ovarian cancer patients: comparison with breast cancer variants in a similar population
}

Florencia C. Cardoso' ${ }^{1}$ Susana Goncalves ${ }^{3}$, Pablo G. Mele², Natalia C. Liria', Leonardo Sganga ${ }^{3}$, Ignacio Diaz Perez ${ }^{3}$, Ernesto J. Podesta ${ }^{2}$ and Angela R. Solano ${ }^{1,2^{*}}$ (D)

\begin{abstract}
Background: Ovarian cancer is the leading cause of death worldwide among gynecologic malignancies. The recent approval of inhibitors of poly (ADP-ribose) polymerase (iPARP) in the treatment of ovarian cancer in the presence of a BRCA1/2 mutation has sparked the analysis of women with such diagnosis, which can further benefit from the detection of carriers in the family. Germline sequence and large rearrangements for BRCA1/2 were tested in 398 consecutive epithelial ovarian cancer (EOC) patients.

The aim of this study was to identify the frequency and spectrum of germline BRCA1/2 pathogenic alterations in a cohort of patients with ovarian serous carcinoma, with a view to adequately selecting patients for prevention through family counseling and correlating this frequency with platinum sensitivity as a guidance to identify patients eligible for iPARP in our population.
\end{abstract}

Results: A total of 96 patients carried a pathogenic germline mutation, accounting for an overall $24.1 \%$ mutation incidence. Among mutation carriers, BRCA1 showed 62.5\% incidence, BRCA2 rendered 36.5\%, and one patient exhibited a mutation in both genes. Three pathogenic mutations were recurrent mutations detected five, three, and four times and represented $12.5 \%$ of the mutated samples. Worth highlighting, a $50 \%$ mutation incidence was detected when breast and ovarian cancer coexisted in the same patient. Novel mutations amounted to 9.4\% of the total mutations, as compared to $4.7 \%$ in breast cancer. Forty out of 60 BRCA1 mutations were beyond the ovarian cancer cluster region (OCCR), in stark contrast with 22 out of 36 BRCA2 mutations being inside the OCCR. Taken together, germline BRCA1/2 mutations in EOC patients showed a distinct mutational spectrum compared to our previously published data on breast cancer patients.

Conclusions: In sum, our study provides novel data on ovarian BRCA1/2 mutation prevalence worldwide, enhances adequate patient selection for family counseling and prevention, and sheds light on the benefits of PARP treatment.

Keywords: Ovarian cancer, BRCA1/2 and ovarian cancer, iPARP treatment

\footnotetext{
*Correspondence: asolano@cemic.edu.ar

'Genotipificación y Cáncer Hereditario, Centro de Educación Médica e Investigaciones Clínicas "Norberto Quirno" (CEMIC), Galván 4102, C1431FWO Ciudad Autonoma de Buenos Aires, Argentina

${ }^{2}$ Instituto de Investigaciones Biomédicas (INBIOMED), Facultad de Medicina,

Universidad de Buenos Aires-CONICET, Paraguay 2155 - Piso 5, C1121ABG

Ciudad Autonoma de Buenos Aires, Argentina

Full list of author information is available at the end of the article
}

(c) The Author(s). 2018 Open Access This article is distributed under the terms of the Creative Commons Attribution 4.0 International License (http://creativecommons.org/licenses/by/4.0/), which permits unrestricted use, distribution, and reproduction in any medium, provided you give appropriate credit to the original author(s) and the source, provide a link to the Creative Commons license, and indicate if changes were made. The Creative Commons Public Domain Dedication waiver (http://creativecommons.org/publicdomain/zero/1.0/) applies to the data made available in this article, unless otherwise stated. 


\section{Background}

Ovarian cancer is the leading cause of death worldwide among gynecologic malignancies. Argentina exhibits midhigh rates, and, in 2016, the National Cancer Institute, Ministry of Health (Instituto Nacional del Cáncer, INC, Ministerio de Salud de la Nación), reported a total of 2274 ovarian cancer cases out of a total of 60,209 women cancer cases, which represents 3.8\% (Argentina, 2016, SIVER-Ca, INC, Ministerio de Salud de la Nación).

Genetic testing for $B R C A 1 / 2$ mutation carriers proves critical to clinical decisions, as more than $90 \%$ of the cases of epithelial ovarian cancer (EOC) are diagnosed with bulky intra-abdominal disease or distant metastases [1]. The importance of $B R C A 1 / 2$ mutation screening in ovarian cancer patients has been further underscored by recent findings showing that mutation carriers have increased sensitivity to inhibitors of poly (ADP-ribose) polymerase (PARP) [2, 3]. In fact, PARP inhibitors (iPARP) have recently been approved for the treatment of advanced ovarian cancer patients carrying either germline or somatic mutations in $B R C A 1 / 2$ genes [4]. Moreover, $B R C A 1 / 2$ mutation status has been shown to predict response to iPARP. Individuals with germline $B R C A 1 / 2$ alterations treated with iPARP have a significant increase in progression-free survival compared with patients with wild-type $B R C A 1 / 2[3,5]$.

The reported prevalence of $B R C A 1 / 2$ mutations in patients with ovarian cancer varies across different studies and ethnic populations. A report interpreting the results of 14 studies from eight Western countries, summarized in a meta-analysis, has shown the overall incidence of germline mutations to be $18.0 \%$ for $B R C A 1$ and $6.9 \%$ for $B R C A 2$, although this incidence ranges between 3.4 and $47 \%$ for $B R C A 1$ and between 1 and $12 \%$ for $B R C A 2$ [6] when considering specific populations. Reports from Asia have revealed the following figures: in South Korea [7], only one pathogenic mutation was found in the BRCA1 gene among 37 EOC patients; a Japanese study [8] found $5.3 \%$ cases with germline mutations in BRCA1 and 7.4\% in BRCA2; in Hong Kong [9], the publication of a series of 60 ovarian cancer patients analyzed for the whole coding region of $B R C A 1$ but only the exon 11 of BRCA2 rendered $11.3 \%$ and $2.1 \%$ patients carrying a mutation, respectively, including the c.1081delG in BRCA1, which seemed to be a founder mutation from Southern Chinese populations, and two recurrent mutations, i.e., c.2371-2372delTG in BRCA1 and c.3337C>T in $B R C A 2$; finally, in the Chinese population [10], the rate of mutation carriers among patients was reported to be $16.7 \%$, with the description of a presumably very frequent non-founder mutation, i.e. c.5470_5477del8 in BRCA1, and the conclusion that the spectrum of $B R C A 1 / 2$ mutations greatly differs from that described in Western studies.
Relatively few studies have been reported on South American populations, and the most readily available results are based on small-size cohorts. A Colombian study has reported 100 patients with ovarian cancer diagnosis and $15 \%$ of mutation detection-13\% in BRCA1 and $2 \%$ in $B R C A 2$-including an $11 \%$ accounting for a founder mutation [11]. A review of Latin American and Caribbean studies summarizes breast/ovarian cancer cases from a few countries. However, only a limited number of studies used full sequencing analysis and ovarian cancer was not clearly disclosed, which prevented the review from reaching conclusions [12].

To gain a more complete insight into the prevalence of $B R C A 1 / 2$ mutations in EOC patients from Argentina, we performed a cohort study of 398 unselected consecutive EOC patients for BRCA1/2 mutation screening using the next-generation sequencing (NGS) approach and multiplex ligation-dependent probe amplification (MLPA) for large rearrangements.

The aim of this study was to identify the frequency and spectrum of germline $B R C A 1 / 2$ pathogenic alterations in a cohort of patients with ovarian serous carcinoma, with a view to adequately selecting patients for prevention through family counseling and correlating this frequency with platinum sensitivity as a guidance to identify patients eligible for iPARP in our population. In addition, and considering similarities in the population analyzed, this study presents a comparison with results previously published by our group [13] on BRCA1/2 mutations in breast cancer patients.

\section{Methods}

\section{Study subjects}

Subjects were selected among women diagnosed with epithelial ovarian cancer and referred to Centro de Educación Médica e Investigaciones Clínicas (CEMIC) for genetic testing from January 2014 to June 2017. A total of 398 patients were included in the study, 299 of whom were selected by the inclusion criteria required for treatment with iPARP (high-grade ovarian serous carcinoma, relapsed, second-line platinum-sensitive). Routine procedure included signing a written informed consent to genetic testing (including anonymized disclosure of the data) from each patient, approved by the Ethics Committee from CEMIC, and a Pretest Counseling for Susceptibility Testing (purpose of testing), as described in the American Society of Clinical Oncology Policy Statement Update [14].

Subjects enrolled in this study showed a mean age at diagnosis of $53.5 \pm 12$ years, within a range of 18 to 84 years of age. Eligible patients included women with newly diagnosed, histologically confirmed, or chemotherapy-treated serous ovarian cancer, regardless of chemotherapy line. Although data on family history $(\mathrm{FH})$ were collected as part of the study, recruitment was independent of $\mathrm{FH}$ conditions. 


\section{$B R C A$ testing}

Genomic DNA of the 398 blood samples was isolated by MagNA Pure ${ }^{\circ}$ LC instrument with total DNA isolation kit I (Roche Diagnostics). Analysis of BRCA1/2 genes included complete sequencing and study of large rearrangements.

The Ion AmpliSeqBRCA1/2 community panel was used for the targeted NGS, as it allows to amplify the entire coding sequences of $B R C A 1$ and $B R C A 2$, including 20-50 bases of adjacent intronic sequence of each exon. Sequencing of the amplified regions was performed with the next-generation platform Personal Genome Machine ${ }^{\circ}$ System. As a control, the STR variants of every sample were previously traced and intra NGS [15] was used to ensure the identification of the sample and avoid possible processing. The few codifying sequences with low readings were analyzed by Sanger reaction in order to reach 100\% coverage.

The raw signal data and the sequence reads were processed with Ion Torrent Suite software (Thermo Fisher Scientific) on a Torrent server. The pipeline included signaling processing, base calling, quality score assignment, adapter trimming, PCR duplicate removal, read alignment to the reference human genome 19, quality control of mapping quality, coverage analysis, and variant calling. Coverage analysis used plug-in software in the Torrent server. The variant caller parameter setting was germline PGM (Life Technologies).

After data analysis, single-nucleotide variants, insertions, deletions, and splice site alternations were registered, and all variants detected were reported. Sanger DNA sequencing was used to confirm all clinically relevant variants detected (classes 3, 4, and 5) using the specific gene primers. Clinical significance was determined according to the report in the reference databases (ClinVar [16], LOVD 3.0 [17], UMD [18]-last access December 29, 2017). For missense mutations not reported or reported with uncertain clinical significance (VUS), in silico programs were used to predict the change in protein function using software Align-GVGD, SIFT, and Mutations Taster.

Large rearrangements were measured by MLPA using SALSA MLPA Probemix P002-D1 and P045-B3 provided by MRC-Holland, and Coffalyser.net software was used for data analysis.

In a preliminary analysis for a panel of genes, 30 samples were exome sequenced and then filtered for the following: ATM, BRCA1, BRCA2, BRIP1, CDH1, CHEK2, MSH2, MLH1, MSH6, PMS2, EPCAM, NBN, NF1, PALB2, PTEN, RAD51C, RAD51D, STK11, and TP53. Full exonic \pm 20 bases of adjacent intronic sequence for each gene were assured. These genes were selected according to the genes listed in the NCCN guidelines (Genetic/Familial High-Risk Assessment: Breast and Ovarian-Version 2.2017), for which there are risk and management recommendations of patients with a pathogenic mutation. In other words, these actionable genes allow clinical measures such as monitoring, treatment, counseling, and prevention for both the probands and their families.

We routinely share our genetic variants and collected at Leiden Open Variation Database (Chapter for Argentina) [19]. In the case of the novel variants, the registration numbers of each of the variants in the LOVD database [17] are shown in Table 2.

\section{Genetic variant classification}

The novel variants were classified according to the recommendation guidelines of the American College of Medical and Genomics (ACMG) [20]. As they correspond to variants not reported in the population and disease database all comply with the PM2 criteria of the ACMG Guidelines, this is a criterion of moderate pathogenicity. According to this:

Probably pathogenic mutations were defined as follows:

1. Nonsense and frameshift variants that generate a premature stop codon, except for the variants that generate a premature stop codon after codon 3326 in the BRCA2 gene (criterion PVS1 of the ACMG guidelines)

2. Splice site variants that are found in intronic or exonic variant in the exon-intron border (criterion PVS1 of the ACMG guidelines)

Variants of uncertain clinical significance (VUS) were defined as follows:

1. Missense variants where multiple lines of computational evidence support to deleterious effect on the gene or gene product or no impact on gene or gene product (criteria PP3 and BP4 respectively of ACMG guidelines)

2. Synonymous (silent) variant for which splicing prediction algorithms predict no impact to the splice consensus sequence nor the creation of a new splice site and the nucleotide is not highly conserved (criterion BP7 ACMG guidelines)

3. Intronic variants distant from the intron-exon boundary

\section{Results}

The sequencing of $B R C A 1 / 2$ in 398 consecutive EOC patients, including 299 patients selected for iPARP treatment, rendered a total of 96 patients carrying a pathogenic germline mutation. These cases are listed in Additional file 1, which indicates patients selected for iPARP treatment in italics and patients with novel mutations in bold. Overall mutation incidence amounted to $24.1 \%(n=398)$, while 
mutation incidence among patients selected for iPARP treatment was $20.7 \%(n=299)$ and mutation incidence among non-iPARP-selected patients was $34.3 \%(n=99)$.

The mutations found were as follows: 60 in BRCA1 (62.5\%), 35 in BRCA2 (36.5\%), and 1 in both genes (1\%) (Table 1). The mean age of diagnosis for the patients carrying a mutation was 53.7 years, which was non-statistically different from 54.3 years in the non-detected-mutation group. The low end of the age range among patients with a non-detected mutation, as well as among patients with both breast and ovary cancer diagnosis was 31 years of age, much higher than that of the mutation-carrying group at 18 years (Table 1 ). Remarkably, the patients diagnosed with both cancers showed a $50 \%$ rate of mutation detection (Table 1), again with similar distribution in both genes: 69\% detected in BRCA1, 27.6\% in BRCA2, and 3.4\% in both genes.

Key to validating our population detection methods and interpretation, only $3.38 \%$ variants were found of unknown significance (VUS). Out of the total number of mutations detected, nine were found to be novel deleterious mutations (9.4\%), three of them in BRCA1 and six in $B R C A 2$, as listed in Table 2. Of note, BRCA1 mutation c.3578_3759delCT has been previously described by our group in an unrelated patient [21], although this patient had breast cancer diagnosed at 31 years; $B R C A 2$ mutation c.7805+2_7805+3delTA has also been already described [13] but is included now as belonging to an ovary cancer patient. Novel intronic variants detected to be yet classified were c. $670+31 \mathrm{~A}>\mathrm{C}, \mathrm{c} .4357+22 \mathrm{C}>\mathrm{T}, \mathrm{c} .80$ $+52 \mathrm{~T}>\mathrm{A}$, and c. $516+3 \mathrm{~A}>\mathrm{T}$.

Regarding recurrent pathogenic mutations, present in 3 or more patients each, 2 were detected in $B R C A 1$ and 1 in $B R C A 2$, including 12 patients among mutation carriers (12.5\%) (Table 3). These recurrent mutations were c.4964_4982del19 and c.5266dupC in BRCA1 and c.5351dupA in BRCA2, with five, three, and four detections, respectively.

The FH group-understood as having at least 1 relative developing breast and/or ovarian cancer among first- or second-degree relatives-accounted for 158 cases, among which 55 rendered mutations (34.8\%), including the patient with a mutation in both genes. In turn, the non-FH group included 105 patients, 10 of whom were mutation carriers (9.5\%). No FH records were available for the remaining 135 patients, 31 of whom revealed a mutation (23.0\%) (Table 4).

Regarding the spectrum of mutations along the genes (Fig. 1), 40 out of 60 mutations detected in BRCA1 were located outside the ovarian cancer cluster region (OCCR), in contrast with the findings for BRCA2, in which 22 out of 36 were located inside the OCCR. In the case of the patient carrying a mutation in the two genes, both mutations were outside the OCCR. These mutations were c.-19-?_80+?del and c.1909+1G $>$ A for $B R C A 1$ and $B R C A 2$, respectively (Additional file 1).

\section{Discussion}

In the current study, we have assessed the $B R C A 1 / 2 \mathrm{mu}-$ tation status in 398 EOC patients with two main goals: the benefits of detecting hereditary breast/ovarian cancer syndrome for prevention and the possibility of selecting patients for treatment with iPARP. Results showed most mutations to be found in the BRCA1 gene, reinforcing once again the well-established association of ovary cancer and a mutation in BRCA1. In our series, however, most of the mutations were outside the region of OCCR of $B R C A 1$, even as the most recent and detailed publication [22] reinforcing the necessity of reporting regional genetic variants [19] and depositing genetic variants in open access databases. The apparent differences with the reported data [22] may very likely due to that no data was included from South America (or may be very little hidden in one of the categories); it is important to remark that the Hispanic demographic group in this very wide population analysis refers to a migration denomination in the USA and does not reflect South America and specifically, our country [13].

Our assay is a comprehensive analysis, and our group has vast experience in the regionality of the mutation spectra in our patients $[13,23]$, which is reflected in the low rate of $3.38 \%$ of VUS found in this series. The frequency of mutations detected reached $24.1 \%$ (Table 1), a value closer to the highest described in the literature $[24,25]$, lower than other published results $[8,11,26-31]$. The 99 patients not selected for iPARP treatment showed a striking proportion of $34.3 \%$ mutation carriers, which may stem from

Table 1 BRCA1/2 sequence: summary of patients analyzed

\begin{tabular}{lllllll}
\hline Diagnosis & $n$ & Age (range) & BRCA mutated (\%) & $\begin{array}{l}\text { BRCA1 mutation } \\
\text { carriers }(n)\end{array}$ & $\begin{array}{l}\text { BRCA2 mutation } \\
\text { carriers }(n)\end{array}$ & Non mutated (\%) \\
\hline EOC (total) & 398 & $53.5(18-84)$ & $96(24.1)$ & $61^{\mathrm{b}}$ & $36^{\mathrm{b}}$ & $302(75.9)$ \\
EOC and BC & 58 & $56.5(31-78)$ & $29(50.0)$ & $21^{\mathrm{b}}$ & $9^{\mathrm{b}}$ & $29(50.0)$ \\
\hline
\end{tabular}

The total number of patients analyzed was diagnosed with epithelial ovarian cancer (398). Among these, 58 patients also had a diagnosis of breast cancer (EOC and BC)

EOC epithelial ovarian cancer, $B C$ breast cancer, $n$ number of cases

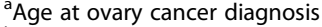

${ }^{\mathrm{b}}$ One of the patients with high-grade ovarian serous carcinoma and breast cancer had a mutation in both genes 
Table 2 Novel variants in BRCA1 (NM_007294.3) and BRCA2 (NM_000059.3) genes detected in 398 probands with diagnosis of epithelial ovarian cancer

\begin{tabular}{|c|c|c|c|c|c|c|c|}
\hline Sample ID & Gene & Exon/intron & Mutation $^{a}$ & Predicted effect $^{\mathrm{b}}$ & MT & $\mathrm{CS}^{\mathrm{C}}$ & LOVD (genomic variant \#) \\
\hline BR1229 & $1 \mathrm{~B}$ & 11 & c.2005dupA & p.(Met669Asnfs*4) & $\mathrm{F}$ & $L P$ & 198881 \\
\hline BR2066 & 1B & 11 & c.3758_3759delCT & p.(Ser1253*) & $\mathrm{F}$ & $L P$ & 196851 \\
\hline BR1037 & $1 \mathrm{~B}$ & 11 & c.876_879delCACT & p.(Thr293Lysfs*4) & $\mathrm{F}$ & $L P$ & 198751 \\
\hline BR1410 & $2 B$ & 11 & c. $2133 C>A$ & p. $($ Cys711*) & $\mathrm{N}$ & $L P$ & 202233 \\
\hline BR0986 & $2 B$ & 11 & c. $2860 \mathrm{G}>\mathrm{T}$ & p.(Glu954*) & $\mathrm{N}$ & LP & 197664 \\
\hline BR0832 & $2 B$ & 11 & c.4419delC & p.(Asn1473Lysfs*6) & $\mathrm{F}$ & $L P$ & 201398 \\
\hline BR2072 & $2 B$ & 11 & C. $5253 \mathrm{C}>\mathrm{A}$ & p. $\left(\operatorname{Tyr} 1751^{*}\right)$ & $\mathrm{N}$ & $L P$ & 203562 \\
\hline BR1464 & $2 B$ & 14 & c.7308delC & p.(Asn2436Lysfs*31) & $\mathrm{F}$ & $L P$ & 206927 \\
\hline BR0495 & $2 B$ & $16 i$ & c.7805+2_7805+3delTA & & $S$ & LP & 199222 \\
\hline BR1104 & 1B & 11 & c. $2357 \mathrm{~T}>\mathrm{C}$ & p.(Leu786Pro) & M & VUS & 200898 \\
\hline BR0889 & $1 \mathrm{~B}$ & 11 & $c .3168 C>T$ & p.(Ser1056=) & Syn & VUS & 200773 \\
\hline BR1061 & $1 \mathrm{~B}$ & $10 \mathrm{i}$ & c. $670+31 A>C$ & & S & VUS & 196392 \\
\hline BR2063 & $1 \mathrm{~B}$ & $13 i$ & c. $4357+22 C>T$ & & S & VUS & 209404 \\
\hline BR1078 & $1 \mathrm{~B}$ & $2 i$ & c. $80+52 \mathrm{~T}>\mathrm{A}$ & & $S$ & VUS & 196406 \\
\hline BR0913 & $2 B$ & $6 i$ & c. $516+3 A>T$ & & S & VUS & 199956 \\
\hline
\end{tabular}

$M T$ mutation type, $F$ frameshift, $N$ nonsense, $S$ splicing, $M$ missense, Syn synonym, $L P$ likely pathogenic, VUS variant of uncertain significance

a HGVS nomenclature at CDNA level

${ }^{b}$ HGVS nomenclature at protein level

${ }^{c} \mathrm{CS}$ : interpretation and classification of the variants was carried out according to the recommendations of the ACMG guidelines

the fact that CEMIC is a reference center for hereditary breast-ovary cancer patient analysis.

The worldwide age range of patients diagnosed with EOC included in $B R C A 1 / 2$ analyses [8, 11, 24-32] starts around 30 years, with the exception of Colombia [11] (16 years) and Argentina [13] (18 years). The lower-end value of the range does not reflect the most frequent age of diagnosis, as cases diagnosed in the patient's sixties are common, frequently with a mutation detected. This is reflected in the similar mean age among all the results published.

The high $50 \%$ rate of $B R C A 1 / 2$ mutations detected in 58 patients with both cancers diagnosis (Table 1) is in line with other studies on similar patients, although in smaller

Table 3 Recurrent mutations in BRCA1/2 detected in 398 probands with epithelial ovarian cancer

\begin{tabular}{ll}
\hline Mutation/times detected & $\begin{array}{l}\text { Unrelated probands } \\
\text { (\% of the total probands) }\end{array}$ \\
\hline BRCA1 & \\
c.4964_4982del19 - p.(Ser1655Tyrfs ${ }^{* 16) / 5}$ & $5(1.3)$ \\
c.5266dupC - p.(Gln1756Profs*74)/3 & $3(0.8)$ \\
BRCA2 & \\
c.5351dupA - p.(Asn1784Lysfs*3)/4 & $4(1.0)$ \\
Total recurrent & $12(3.1)$ \\
Total recurrent (12)/total mutated & - \\
(96) $=12.5 \%$ & \\
\hline
\end{tabular}

numbers, such as the Japanese study with 3 cases [8], all with a mutation detected. This is also in agreement with our previous publication [13], in which we analyzed 14 patients with breast and ovary cancer, 11 of whom (78.6\%) bore a pathogenic mutation. Interestingly, seven mutations were found in common with the current series of patients, as follows: c.211A >G, c.1687C $>$ T, c.1892dupT, c.5266dupC, c.5468-1G>A, c.2808_2811delACAA, and c.5351dupA (Additional file 1).

Worth pointing out, the gene spectrum (Fig. 1), including data on the OCCR and the recurrent mutations described (Table 3), does not visualize a panel or hot spot of mutations to abbreviate the analysis of $B R C A 1 / 2$ in our ovarian cancer population.

As an additional comment regarding FH (not included in the criteria for the selection of patients), complementary data in the analysis of the results reveals large differences obtained in mutation detection between the $\mathrm{FH}$ and non-FH groups $(34.8 \%$ vs $9.5 \%, p$ value $=0.000003$, significant at $p<0.05)$, which is in contrast with results previously published [8]. This discrepancy may be explained by the larger number of patients studied in our report (398 vs 95), and our higher rate of mutations detected ( $24.1 \%$ vs $12.6 \%)$.

In turn, the following observations when comparing the findings described for ovarian cancer patients with our previous publication including a vast majority of breast cancer patients [13] are as follows: (a) the rate of 
Table 4 Family history in patients with epithelial ovarian cancer

\begin{tabular}{lll}
\hline Family history & $\begin{array}{l}\text { Number of probands } \\
\text { (\% of total) }\end{array}$ & $\begin{array}{l}\text { Patients with a mutation } \\
\text { detected (\%) }\end{array}$ \\
\hline Yes $^{\mathrm{a}}$ & $158(39.7)$ & $55(34.8)$ \\
No & $105(26.4)$ & $10(9.5)$ \\
Not known & $135(33.9)$ & $31(23.0)$ \\
\hline
\end{tabular}

${ }^{a}$ Yes: family history with at least 1 relative developing breast and/or ovarian cancer among first- or second-degree relatives

mutation detection was higher in ovarian cancer patients with $24.1 \%$ vs breast cancer with $19.04 \%$ ( $p$ value = 0.035611 , significant at $p<0.05$ ); (b) the rate of novel mutations showed a tendency: $9.4 \%$ for ovarian cancer vs $4.7 \%$ for breast cancer. The population analyzed was 398 subjects for ovary cancer and 940 subjects for breast cancer with a detection rate of $2.26 \%$ (9 out 398) and $0.85 \%$ ( 8 out 940$)$ novel variants, respectively ( $p$ value $=$ 0.035249 , significant at $p<0.05$ ); (c) the rate of recurrent mutations was similar for both groups. Interestingly, the spectrum of recurrent mutations for both genes was spread along both genes.

A promising turn in the treatment of ovarian cancer has been the attempt at repairing double-strand DNA damage by homologous recombination repair pathway (HRR) mechanisms. BRCA1 and BRCA2 are genes centrally involved in this process, and mutations resulting in damaged $B R C A 1$ or $B R C A 2$ proteins can lead to various types of cancer such as breast, ovarian, or prostate cancer among the most closely associated. Even in the presence of a pathogenic mutation in $B R C A$, single-strand break repair by non-homologous end joining is an alternative pathway to repair double-strand breaks, avoiding cell death pathways like apoptosis. iPARP cause HRR leading gene-deficient (including $B R C A 1 / 2$ ) cancer cells to die by apoptosis. This is known as "synthetic lethality," a concept developed upon evidence on sensitivity of $B R C A 1 / 2$ defective cells to platinum salts [33, 34].

Preliminary results from exome analysis of a panel of genes (see the "Methods" section) in 30 patients showed the following non-BRCA1/2 mutations: in EPCAM, c.412C $>\mathrm{T}$ p.(Arg138*), and coexisting mutations as follows: in MUTYH, c.1105delC - p.(Ala371Profs*23) and in heterozygosis and $R A D 51 D$, c. $1 \mathrm{~A}>\mathrm{G}$ p.(Met1Val). The application of these results is still under consideration, although the involvement of the RAD51D gene in the HRR mechanism should be highlighted.

\section{Conclusion}

In sum, the strength of our study lies in the inclusion of 299 patients exclusively selected for treatment with iPARP, plus an extra of 99 cases which could also benefit from treatment, the use of thorough methodology and

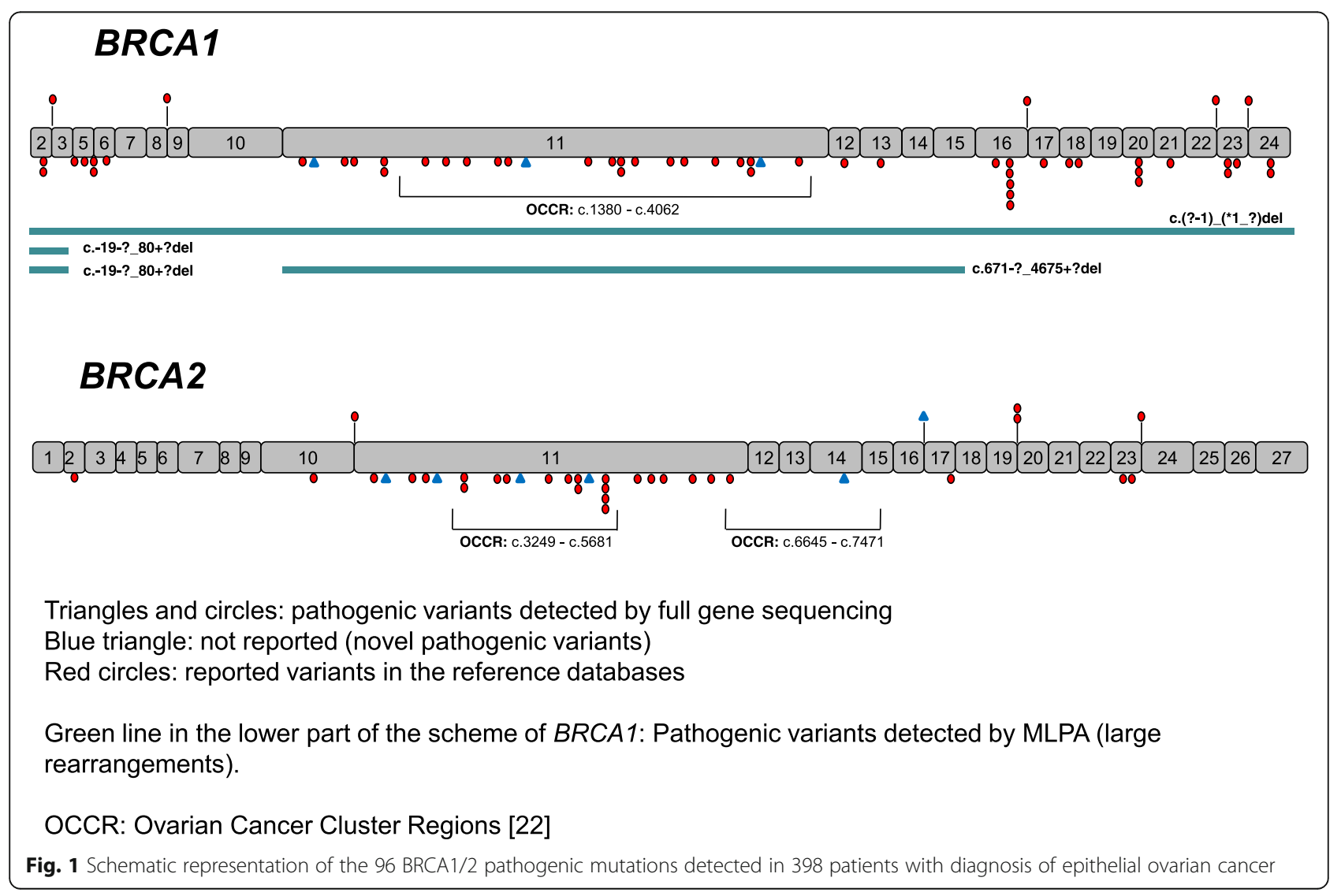


knowledge of our population regional variants [13, 23], as supported by the $3.38 \%$ of VUS found. The findings reported here thus offer $B R C A$ mutation carriers the benefit of treatment possibilities and allow precise identification of hereditary breast-ovary disease and the preventive measures associated.

\section{Additional file}

Additional file 1: Pathogenic mutations in BRCA1 (NM_007294.3) and BRCA2 (NM_000059.3) genes $(n=96)$ detected in 398 probands with diagnosis of epithelial ovarian cancer. (DOCX $31 \mathrm{~kb}$ )

\section{Abbreviations}

EOC: Epithelial ovarian cancer; NGS: Next-generation sequencing; OCCR: Ovarian cancer cluster region; PARP inhibitors: Poly (ADP-ribose) polymerase inhibitors

\section{Acknowledgements}

The authors are grateful to all the women who participated in this study. We also want to thank the clinic team for the careful selection and dedication to the patient attention, specially to Angel Martin, Arroyo Gerardo, Bas Carlos, Bruno Luisina, Caceres Valeria, Crimi Gabriel, Caminos Facundo, Colica Maria, Damiano Mario, De La Vega Maximo, Diaz Canton Enrique, Dodyk Patricia, Escudero Miguel, Fernandez Leyes Marcelo, Garrido Rosa, Gomez Abuin Gonzalo, Greco Martin, Ivulich Carlos, Kalfayan Pablo, Lacava Juan, Levit Patricio, Llugdar Jose, Mainella Andrea, Mampel Alejandra, Marmissolle Fabiana, Masllorens Francisca, Perazzo Florencia, Petracci Fernando, Real Nilda, Recondo Gonzalo, Richardet Martin, Riggi Maria, Santillan Francisco, Trigo Valeria, Yanzi Alvaro, and Zeff Natalia. We thank María M. Rancez for providing language help and writing assistance.

\section{Funding}

This study is partially funded by grant from the Instituto Nacional del Cáncer, Ministerio de Salud de la República Argentina, Res. 0515.

\section{Availability of data and materials}

The datasets generated and/or analyzed during the current study are available in the additional file and at Leiden Open Variation Database (Chapter for Argentina: ar.LOVD.org) [19].

\section{Authors' contributions}

AS, FC, and EP had full access to all the data in the study and take responsibility for the integrity of the data and the accuracy of the data analysis. AS, FC, SG, and EP provided the study concept and design. FC, NL, and LS are responsible for the patients sample organization and collection. PM, IDP, and LS contributed to the literature analysis and statistical evaluation. AS, FC, SG, and EP did the acquisition, analysis, and interpretation of the data. All authors critically revised the manuscript for important intellectual content. All authors read and approved the final manuscript.

\section{Ethics approval and consent to participate}

Routine procedure included signing a written informed consent to genetic testing (including anonymized disclosure of the data) from each patient, approved by the Ethics Committee from CEMIC and a Pretest Counseling for Susceptibility Testing (purpose of testing), as described in the American Society of Clinical Oncology Policy Statement Update.

\section{Competing interests}

SG is the medical director in AstraZeneca Argentina and Uruguay MC. LS is the diagnosis manager in AstraZeneca Argentina MC. IDP is the oncology medical manager in AstraZeneca Argentina and Uruguay MC. The other authors declare that they have no competing interest.

\section{Publisher's Note}

Springer Nature remains neutral with regard to jurisdictional claims in published maps and institutional affiliations.

\section{Author details}

"Genotipificación y Cáncer Hereditario, Centro de Educación Médica e Investigaciones Clínicas "Norberto Quirno" (CEMIC), Galván 4102, C1431FWO Ciudad Autonoma de Buenos Aires, Argentina. Instituto de Investigaciones Biomédicas (INBIOMED), Facultad de Medicina, Universidad de Buenos Aires-CONICET, Paraguay 2155 - Piso 5, C1121ABG Ciudad Autonoma de Buenos Aires, Argentina. ${ }^{3}$ AstraZeneca Argentina MC, Vedia 3616, C1430DAH Ciudad Autonoma de Buenos Aires, Argentina.

Received: 9 March 2018 Accepted: 30 July 2018

Published online: 13 August 2018

\section{References}

1. Hoskins WJ. Prospective on ovarian cancer: why prevent? J Cell Biochem Suppl. 1995;23:189-99.

2. Audeh MW, Carmichael J, Penson RT, Friedlander M, Powell B, Bell-McGuinn KM, Scott C, Weitzel JN, Oaknin A, Loman N, et al. Oral poly(ADP-ribose) polymerase inhibitor olaparib in patients with BRCA1 or BRCA2 mutations and recurrent ovarian cancer: a proof-of-concept trial. Lancet. 2010; 376(9737):245-51.

3. Ledermann J, Harter P, Gourley C, Friedlander M, Vergote I, Rustin G, Scott C, Meier W, Shapira-Frommer R, Safra T, et al. Olaparib maintenance therapy in platinum-sensitive relapsed ovarian cancer. N Engl J Med. 2012;366(15): 1382-92.

4. Kim G, Ison G, McKee AE, Zhang H, Tang S, Gwise T, Sridhara R, Lee E, Tzou A, Philip R, et al. FDA approval summary: olaparib monotherapy in patients with deleterious germline BRCA-mutated advanced ovarian cancer treated with three or more lines of chemotherapy. Clin Cancer Res. 2015;21(19): $4257-61$.

5. Ledermann JA, Drew Y, Kristeleit RS. Homologous recombination deficiency and ovarian cancer. Eur J Cancer. 2016;60:49-58.

6. Zhong $\mathrm{Q}$, Peng HL, Zhao X, Zhang L, Hwang WT. Effects of BRCA1- and BRCA2-related mutations on ovarian and breast cancer survival: a metaanalysis. Clin Cancer Res. 2015;21(1):211-20.

7. Kim YT, Nam EJ, Yoon BS, Kim SW, Kim SH, Kim JH, Kim HK, Koo JS, Kim JW. Germline mutations of BRCA1 and BRCA2 in Korean sporadic ovarian carcinoma. Gynecol Oncol. 2005;99(3):585-90.

8. Sakamoto I, Hirotsu Y, Nakagomi H, Ouchi H, Ikegami A, Teramoto K, Amemiya $\mathrm{K}$, Mochizuki H, Omata M. BRCA1 and BRCA2 mutations in Japanese patients with ovarian, fallopian tube, and primary peritoneal cancer. Cancer. 2016;122(1):84-90.

9. Khoo US, Ngan HY, Cheung AN, Chan KY, Lu J, Chan WW, Lau S, Andrulis IL, Ozcelik H. Mutational analysis of BRCA1 and BRCA2 genes in Chinese ovarian cancer identifies 6 novel germline mutations. Hum Mutat. 2000; 16(1):88-9.

10. Khoo US, Chan KY, Cheung AN, Xue WC, Shen DH, Fung KY, Ngan HY, Choy $\mathrm{KW}$, Pang $\mathrm{CP}$, Poon $\mathrm{CS}$, et al. Recurrent BRCA1 and BRCA2 germline mutations in ovarian cancer: a founder mutation of BRCA1 identified in the Chinese population. Hum Mutat. 2002;19(3):307-8.

11. Rodriguez AO, Llacuachaqui M, Pardo GG, Royer R, Larson G, Weitzel JN, Narod SA. BRCA1 and BRCA2 mutations among ovarian cancer patients from Colombia. Gynecol Oncol. 2012;124(2):236-43.

12. Dutil J, Golubeva VA, Pacheco-Torres AL, Diaz-Zabala HJ, Matta JL, Monteiro AN. The spectrum of BRCA1 and BRCA2 alleles in Latin America and the Caribbean: a clinical perspective. Breast Cancer Res Treat. 2015;154(3):441-53.

13. Solano AR, Cardoso FC, Romano V, Perazzo F, Bas C, Recondo G, Santillan $\mathrm{FB}$, Gonzalez $\mathrm{E}$, Abalo $\mathrm{E}$, Viniegra $\mathrm{M}$, et al. Spectrum of BRCA1/2 variants in 940 patients from Argentina including novel, deleterious and recurrent germline mutations: impact on healthcare and clinical practice. Oncotarget. 2017:8(36):60487-95.

14. Robson ME, Bradbury AR, Arun B, Domchek SM, Ford JM, Hampel HL, Lipkin SM, Syngal S, Wollins DS, Lindor NM. American Society of Clinical Oncology policy statement update: genetic and genomic testing for cancer susceptibility. J Clin Oncol. 2015;33(31):3660-7.

15. Marqués JM, Repetto L, Guggeri V, Russo E, García A, Agorio A, Torres A, Azambuja CJ. Sample ID quality control and methodological improvements for NGS gene panels. In: 65th Annual Meeting of The American Society of Human Genetics. (Abst.1959F); 2015.

16. ClinVar, National Center for Biotechnology http://www.ncbinlm.nih.gov/dinvar/. Accesed 29 Dec 2017 
17. Leiden Open Variation Database 3.0. https://databases.lovd.nl/shared/genes. Accesed 29 Dec 2017.

18. Universal Mutation Database http://www.umd.be/. Accesed 29 Dec 2017.

19. Leiden Open Variation Database (Chapter for Argentina). http://ar.lovd.org. Accesed 29 Dec 2017.

20. Richards S, Aziz N, Bale S, Bick D, Das S, Gastier-Foster J, Grody WW, Hegde M, Lyon E, Spector E, et al. Standards and guidelines for the interpretation of sequence variants: a joint consensus recommendation of the American College of Medical Genetics and Genomics and the Association for Molecular Pathology. Genet Med. 2015;17(5):405-24.

21. Solano AR, Aceto GM, Delettieres $D$, Veschi S, Neuman Ml, Alonso E, Chialina S, Chacon RD, Renato MC, Podesta EJ. BRCA1 and BRCA2 analysis of Argentinean breast/ovarian cancer patients selected for age and family history highlights a role for novel mutations of putative south-American origin. SpringerPlus. 2012;1:20.

22. Rebbeck TR, Mitra N, Wan F, Sinilnikova OM, Healey S, McGuffog L, Mazoyer S, Chenevix-Trench G, Easton DF, Antoniou AC, et al. Association of type and location of BRCA1 and BRCA2 mutations with risk of breast and ovarian cancer. JAMA. 2015;313(13):1347-61.

23. Aceto GM, Solano AR, Neuman Ml, Veschi S, Morgano A, Malatesta S, Chacon RD, Pupareli C, Lombardi M, Battista P, et al. High-risk human papilloma virus infection, tumor pathophenotypes, and BRCA1/2 and TP53 status in juvenile breast cancer. Breast Cancer Res Treat. 2010;122(3):671-83.

24. Gallagher DJ, Konner JA, Bell-McGuinn KM, Bhatia J, Sabbatini P, Aghajanian CA, Offit K, Barakat RR, Spriggs DR, Kauff ND. Survival in epithelial ovarian cancer: a multivariate analysis incorporating BRCA mutation status and platinum sensitivity. Ann Oncol. 2011;22(5):1127-32.

25. Vencken PM, Kriege M, Hoogwerf D, Beugelink S, van der Burg ME, Hooning MJ, Berns EM, Jager A, Collee M, Burger CW, et al. Chemosensitivity and outcome of BRCA1- and BRCA2-associated ovarian cancer patients after first-line chemotherapy compared with sporadic ovarian cancer patients. Ann Oncol. 2011;22(6):1346-52.

26. Yang D, Khan S, Sun Y, Hess K, Shmulevich I, Sood AK, Zhang W. Association of BRCA1 and BRCA2 mutations with survival, chemotherapy sensitivity, and gene mutator phenotype in patients with ovarian cancer. JAMA. 2011; 306(14):1557-65.

27. Alsop K, Fereday S, Meldrum C, deFazio A, Emmanuel C, George J, Dobrovic A, Birrer MJ, Webb PM, Stewart C, et al. BRCA mutation frequency and patterns of treatment response in BRCA mutation-positive women with ovarian cancer: a report from the Australian Ovarian Cancer Study Group. $J$ Clin Oncol. 2012;30(21):2654-63.

28. Dann RB, DeLoia JA, Timms KM, Zorn KK, Potter J, Flake DD 2nd, Lanchbury JS, Krivak TC. BRCA1/2 mutations and expression: response to platinum chemotherapy in patients with advanced stage epithelial ovarian cancer. Gynecol Oncol. 2012;125(3):677-82.

29. McLaughlin JR, Rosen B, Moody J, Pal T, Fan I, Shaw PA, Risch HA, Sellers TA, Sun P, Narod SA. Long-term ovarian cancer survival associated with mutation in BRCA1 or BRCA2. J Natl Cancer Inst. 2013;105(2):141-8.

30. Shi T, Wang P, Xie C, Yin S, Shi D, Wei C, Tang W, Jiang R, Cheng X, Wei Q, et al. BRCA1 and BRCA2 mutations in ovarian cancer patients from China: ethnic-related mutations in BRCA1 associated with an increased risk of ovarian cancer. Int J Cancer. 2017;140(9):2051-9.

31. Hyman DM, Long KC, Tanner EJ, Grisham RN, Arnold AG, Bhatia J, Phillips MF, Spriggs DR, Soslow RA, Kauff ND, et al. Outcomes of primary surgical cytoreduction in patients with BRCA-associated high-grade serous ovarian carcinoma. Gynecol Oncol. 2012;126(2):224-8.

32. Pennington KP, Walsh T, Harrell Ml, Lee MK, Pennil CC, Rendi MH, Thornton A, Norquist BM, Casadei S, Nord AS, et al. Germline and somatic mutations in homologous recombination genes predict platinum response and survival in ovarian, fallopian tube, and peritoneal carcinomas. Clin Cancer Res. 2014:20(3):764-75.

33. Fedier A, Steiner RA, Schwarz VA, Lenherr L, Haller U, Fink D. The effect of loss of Brca1 on the sensitivity to anticancer agents in p53-deficient cells. Int J Oncol. 2003;22(5):1169-73.

34. Evers B, Drost R, Schut E, de Bruin M, van der Burg E, Derksen PW, Holstege $\mathrm{H}$, Liu X, van Drunen E, Beverloo HB, et al. Selective inhibition of BRCA2deficient mammary tumor cell growth by AZD2281 and cisplatin. Clin Cancer Res. 2008;14(12):3916-25.

\section{Ready to submit your research? Choose BMC and benefit from}

- fast, convenient online submission

- thorough peer review by experienced researchers in your field

- rapid publication on acceptance

- support for research data, including large and complex data types

- gold Open Access which fosters wider collaboration and increased citations

- maximum visibility for your research: over $100 \mathrm{M}$ website views per year

At BMC, research is always in progress.

Learn more biomedcentral.com/submissions 